\title{
Perceptions Of Lecturing Staff On Social Media Networking Systems And Their Use Of It
}

Johannes A. Wiid, University of South Africa (UNISA), South Africa Corinne E. Nell, University of South Africa (UNISA), South Africa

Michael C. Cant, University of South Africa (UNISA), South Africa

\begin{abstract}
The advent of technology has led to a major change in the delivering of knowledge and lecturers are in the forefront of this. No longer can projectors or black boards solely be used as a means of communication, as the student of the new millennia is an astute user of technology. Lecturers and students are both therefore expected to make use of technology in the transfer of knowledge and academic interaction. Students have a right to expect their lecturers, and the institution that they study at, to incorporate the latest technology in the delivery of their qualifications. The main aim of this study was to determine lecturers' perceptions on social media networking systems and their use of it in an academic context. The study also focussed on whether lecturers make use of, and believes in, social media networking systems as an effective tool to use in teaching and in providing study content and material to students. These were tested by making use of the Technology Acceptance Model (TAM) constructs namely; 'Perceive ease of use', 'Perceived usefulness', 'Attitude towards using', 'Intention to use', and 'System accessibility'. A survey was distributed to lecturers, and it was found that social media is being used by the majority of lecturers, but more for social purposes than educational purposes. It was also found that Facebook is the most popular social media networking system to use.
\end{abstract}

Keywords: Social Media; Social Media Networking Systems; Tertiary Institutions; Teaching; Lecturers, Students; Perceptions

\section{INTRODUCTION AND OBJECTIVES OF THE STUDY ${ }^{1}$}

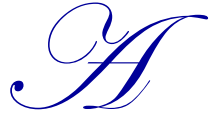

cademic institutions that have not embraced change - and more specifically technological change in their mode of tuition delivery will soon be regarded as dinosaurs. Technology, and by implication social media, has revolutionised all forms of communication and students are not satisfied with a one dimensional offering of knowledge. The larger mobile phone companies have embraced this fact in their product planning and development and that is why there is a constant stream of newer and better applications on a regular basis. Students form a major target market for these companies which by implication mean that they expect academic institutions to make use of these technologies in their contact with them. The use of internet-based social media networking systems have enabled companies, consumers, institutions and many more to communicate faster and more effectively with people around the world about a specific topic, product or issue at any point in time (Mangold \& Faulds, 2009:357). Social media has grown in leaps and bounds over the past few years as a networking system which offers all types of organisations and institutions, such as universities, to communicate with their consumers or clients. In a similar way it also makes it easier for tertiary institutions to communicate related course work to their students, to encourage discussion between and among students and to address administrative issues (Moran, Seaman \& Tinti-Kane, 2011:4; Adamson, 2012). Shen, Laffey, Lin and Huang

\footnotetext{
${ }^{1}$ This study is a follow up on a similar study conducted by the authors entitled: "Perceptions and Uses of Social Media Networking Systems by South African Students", published in the International Business \& Economics Research Journal (Wiid, Nell \& Cant, 2014:715-725). As the general theme is very similar to this article some overlap in the theoretical discussion will occur.
} 
(2006:270) are of the opinion that online learning through means of various social media networking systems have become a very common educational format to use by both tertiary institutions and their students around the world. The main reason for this lies in the fact that it offers flexibility of time and place - something that is regarded as unique in today's world of learning. Social media networking systems have the ability to enable lecturers and students to collaborate and share information at any time convenient to them and from any place in the world (Adamson, 2012).

Adamson (2012) confirms that social media networking systems are destined to focus education on the group instead of the individual, but that students' individual learning experience is improved through collaboration and informal learning with their peers. However, not all authors are positive regarding social media networking in education and have expressed their reservations in this regard. Picardo (2011:1) sees the use of social media networking systems in the tertiary institution as something that can lead to a loss of control in the education sphere as it can be highly disruptive. This may be attributed to the fact that students are more familiar with using different social media tools than the lecturers (Picardo, 2011:1).

Picardo, (2011) expressed another concern, namely one of aversion due to a lack of knowledge by lecturers on the functioning of social media networking systems. This aversion may lead to the non-use of social media networking systems in tuition. A previous study by Wiid, Nell and Cant (2014:715-725), concerning the wishes of students with regards to the use of social media as an educational tool found that they would prefer interaction via social media.

The purpose of this study is to determine lecturers' perception on social media networking systems and their willingness and inclination to use it. This study aims to determine, within the context of an open distance learning institution, the following:

- $\quad$ The perceptions of lecturers on social media as a lecturing tool.

- The utilisation of social media by lecturers.

- $\quad$ The relationship between social media as a lecturing tool and the private use of social media by lecturers.

The following section gives an overview of social media networking systems, the uses of social media networking systems, as well as a review on the utilisation thereof by students. The empirical findings and the discussion of the findings appear in the latter part of the paper.

\section{OVERVIEW OF SOCIAL MEDIA NETWORKING SYSTEMS}

\section{Defining Social Media}

Social media is defined by Boyd and Ellison (2008:211) as, “... web-based services that allow individuals to construct a public or a semi-public profile within a bounded system, articulate a list of other users with whom they share a connection and view and traverse their list of connections and those made by others within the system". Mangold and Faulds (2009:357) on the other hand define social media or 'consumer-generated media' as, “... a variety of new sources of online information that are created, initiated, circulated and used by consumers' intent on educating each other about products, brands, services, personalities and issues".

It is clear from these definitions that social media networking systems include various online, and word-ofmouth forums which also include blogs, company-sponsored discussion boards and chat rooms, consumer-toconsumer email, consumer product or service ratings websites and forums, internet discussion boards and forums, moblogs (sites containing digital audio, images, movies, or photographs), and social networking websites, to name only a few (Mangold \& Faulds, 2009:358).

According to Larson (2012) the five most popular social media networking systems used and accepted in the market are; Facebook with 901 million users, Twitter with 555 million users, Google+ with 170 million users, LinkedIn with 150 million users, and lastly Pinterest with 11.7 million users. 
It was indicated by Adamson (2012) that social media networking systems are perceived as being an important tool for learning and that it should be used more for this purpose. Advantage should be taken, due to the fact that nowadays more students and some lecturers are more familiar with social media networking systems and should therefore use various social media networking systems as a platform for communication, learning and collaboration, as well as sharing ideas and topics of interest (Adamson, 2012). There are plenty uses and benefits of using social media networking systems and it is critical that both the students and the lecturers should be aware of these. Knowing the different uses and benefits will enable both the students and lecturers to communicate more effectively with each other in a more, flexible and faster way (Shen et al., 2006:270).

\section{The Use And Benefits Of Social Media Networking Systems}

Jackson (2011) indicated that the use of social media networking systems in classrooms can have a positive psychological effect on both the students and the lecturers. As soon as students were allowed to answer questions by means of using, for example Twitter, they felt less pressured even though the answer was wrong.

The uses and benefits of social media networking systems should therefore be taken into consideration by tertiary institutions. These uses and benefits are as follows (Lepi, 2012):

\section{Facebook}

- Improve communication by enabling students to easily contact lecturers and other students with questions

- Easily integrate class projects with Facebook through the sharing of books, reviews and promoting student work

- Use Facebook applications and groups in order to make learning and studying easier and more enjoyable for students

- Create a Facebook page where you can schedule events, post notes and remind students of important dates and due dates

- Be a news source by posting status updates and follow other media and well-known leaders

Twitter

- Post additional materials such as links to articles and videos in order for students to continue with their learning even if classes are over

- Setting-up specific feeds to enable all students to see and monitor certain events

- Develop a feed for your students in order to tweet about important dates, upcoming events and assignments, as well as class news

- Connect with other students, lecturers, as well as parents in order to increase communication and build community

- Follow tweets of other lecturers' in order to keep up with the latest teaching trends, to get ideas and to support one another

- Share ideas and collaborate with lecturers and students from other classes, schools and departments

Pinterest

- Use community boards for group projects, as well as brainstorming to enable a number of users to save their resources in one place

- Allow and encourage students to use Pinterest for presentations and projects

- Search for inspiring tips on how to organise and decorate your classroom

- Search, find, pin and organise images, projects, videos, stories etc. for future classes and projects 
YouTube

- Search for video-clips under specific topics that can be used in the classroom to give a lesson in a more memorable way

- Organise playlists to enable students to easily find and watch all relevant and approved videos on a topic

- Record lessons and post them on YouTube in order for students to review them whenever they want to

- Create interactive videos by adding quizzes, comments etc. to it

According to Picardo (2011) students' perceptions and use of technology will play a role in the use or disuse of social media networking systems in tertiary institutions. The question still to be answered is; 'Do lecturers wish to interact with their students online?' The answer to this question may be more complex than it initially appears to be, as the participation of lecturers in a social media networking system should be voluntary in order to ensure that the necessary quality of interaction and cooperation is obtained for it to improve teaching and learning (Picardo, 2011).

Picardo (2011) further argues that social media networking systems challenge the ability of both lecturers and students to interact and collaborate successfully via this medium, meaning that when it comes to academia, students do not feel comfortable with the degree of transparency needed in order for the social media networking systems to be effective.

In order to determine the lecturers' perceptions on the use of social media networking systems in tertiary institutions (higher education), the five constructs of the Technology Acceptance Module was studied. These are discussed in the next section.

\section{TECHNOLOGY ACCEPTANCE MODEL}

The Technology Acceptance Model (TAM) is an information system (a system that consists of all the network communication channels used within an organisation) theory that demonstrates how users accept and use specific technology (Davis, 1993:475). The model indicates that when users are confronted with a new software package, various factors influence their decision about how and when they will use this specific technology (Mazhar, 2006). Davis, Bagozzi and Warshaw (1989:985) indicated that user motivation can be explained by three constructs; 'Perceived ease of use', 'Perceived usefulness', and 'Attitude toward using the system'.

'Perceived usefulness' which is the first construct is described according to Davis (1993:477) as, “... the degree to which an individual believes that using a particular system would enhance his or her job performance". The second construct is 'Perceived ease of use' which is defined as, "... the degree to which an individual believes that using a particular system would be free from effort" (Davis, 1993:477). The third construct- "Attitude towards using' is defined as, "... the degree of evaluative affect that an individual associates with using the target system in his or her job" (Davis, 1993:477). 'System accessibility' was the fourth construct that was tested, which refers to organisational context variables, and lastly was of the construct- 'Intention to Use', which refers to the degree to which a person has created a conscious plan to perform or not perform a future behaviour (Venkatesh, 2013).

These constructs were imbedded in the research study. The next section deals with the research methodology and the findings of the research.

\section{RESEARCH METHODOLOGY}

In determining the perceptions of lecturers on social media, a questionnaire was developed for this study. The questionnaire mostly incorporated questions that are of quantitative nature. The questionnaires were distributed among the lecturing staff of a leading South African University and a total of 204 correctly completed questionnaires were received. The demographic profile of the respondent group is presented in Table 1. The majority of lecturers (41.92 per cent) were between 26 and 35 years of age. The gender split for the respondent group is female dominated, with 55 per cent of lecturers being female. 
Table 1. Demographic Profile

\begin{tabular}{|c|c|c|}
\hline Age Group & \% of Total & $\mathbf{N}$ \\
\hline$<35$ years & $46.46 \%$ & 92 \\
\hline 36 - 50 years & $33.33 \%$ & 66 \\
\hline $51+$ years & $20.20 \%$ & 40 \\
\hline \multicolumn{3}{|l|}{ Gender } \\
\hline Male & $44.67 \%$ & 88 \\
\hline Female & $55.33 \%$ & 109 \\
\hline
\end{tabular}

\section{RESULTS}

\section{Lecturers' Perception And Acceptance Of Social Media As A Lecturing Tool}

Lecturers' perception and acceptance of social media as lecturing tool is based on 21 statements borrowed from the Technology Acceptance Model (TAM). Respondents were asked to rate the 21 statements on a seven point Likert scale ( 1 being "Strongly disagree" and 7 being "Strongly agree"). The 21 statements are structured as five sub-constructs, 'Perceived ease of use'; 'Perceived usefulness'; 'Attitude towards using'; 'Intention to use' and 'System accessibility'.

For each sub-construct a mean was calculated to assess the level of agreement among sub-constructs. Table 2 shows the means and standard deviations.

Table 2. Sub-Constructs - Means; Standard Deviations And Cronbach's Alpha

\begin{tabular}{lccc}
\hline Sub-Construct & Mean & Std Dev & Cronbach's alpha \\
\hline Ease of use score & 5.23 & 1.35 & 0.93 \\
Usefulness score & 4.81 & 1.31 & 0.91 \\
Attitude score & 5.11 & 1.32 & 0.88 \\
Intention score & 4.43 & 1.58 & 0.94 \\
Accessibility score & 5.31 & 1.41 & None \\
\hline
\end{tabular}

'Accessibility' was considered most important with a mean of 5.31, while 'Intention' were least important with a mean of 4.43. The means were however closely distributed indicating a general agreement on the importance of all the sub-constructs. The standard deviations are fairly high indicating variation in agreement among subconstructs. The Cronbach's alpha for the sub-constructs all yielded high Cronbach's alpha values $(>=0.80)$ indicating good reliability. Please note that Accessibility is only one item and cannot be tested for reliability.

\section{Profiling The Views Of Respondents On Social Media:}

The biographical variables age, gender and population group were tested against the sub-constructs for significant different views. Of the biographical variables tested only age group showed significant different views.

\section{Comparison Of The Respondents Views On The Five Sub-Constructs Among Age Groups}

Figure 1 below, is a profile plot from multivariate analysis of variance (MANOVA). It is used in order to explore differences between the different sub-constructs mean scores of lecturers of different age groups. 


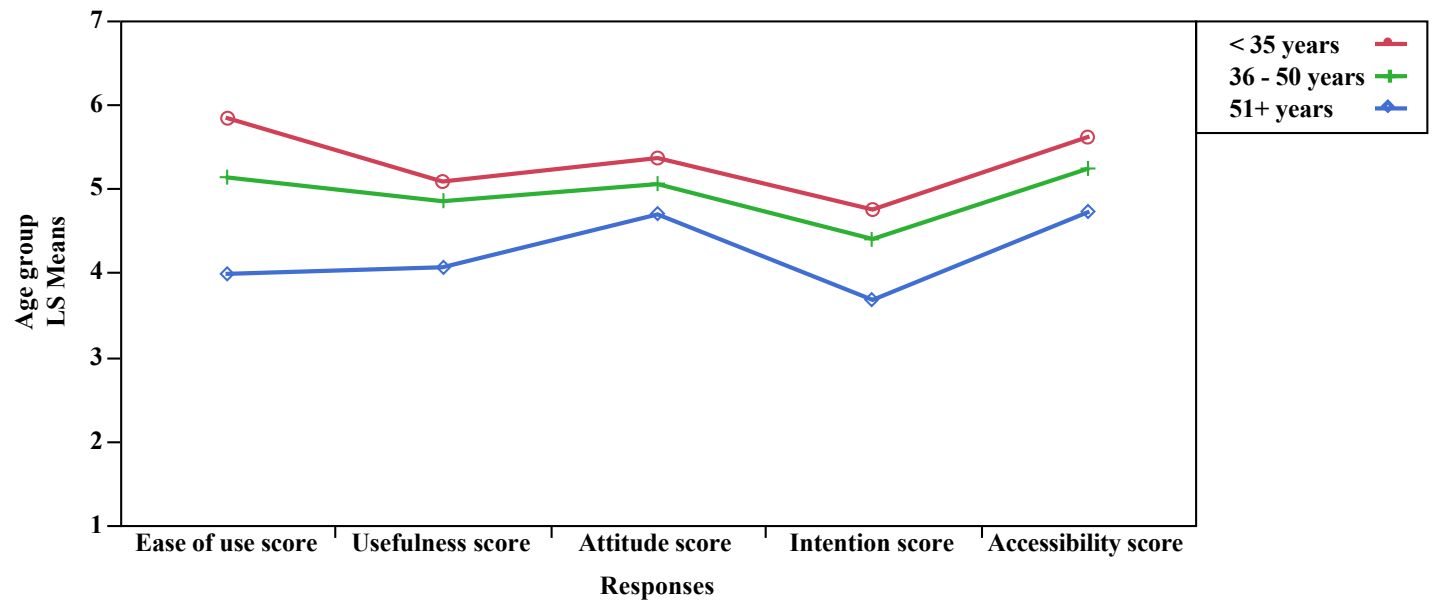

Figure 1. Lecturers Of Different Age Groups On The Five Sub-Constructs

From Figure 1 it is clear that there is a difference between the age groups. Younger respondents seemed to view the sub-constructs of social media more important than older age groups.

In order to develop a profile of the different age groups, the following descriptive statistics, as observed from Table 3, should be taken into consideration.

Table 3. Sub-Constructs - Mean Score by Age Group

\begin{tabular}{lccccc}
\hline Age group & Ease Of Use & Usefulness & Attitude & Intention & Accessibility \\
\hline$<35$ years & 5.84 & 5.09 & 5.36 & 4.77 & 5.62 \\
36 - 50 years & 5.13 & 4.88 & 5.07 & 4.44 & 5.22 \\
$51+$ years & 4.02 & 4.09 & 4.69 & 3.69 & 4.72 \\
\hline
\end{tabular}

From Table 3 it is clear that the younger respondents <35 years have the highest scores on all the constructs, while the older group $51+$ years have the lowest scores on all the constructs.

In order to determine whether these differences between the means of the age-groups are statistically significant, separate Analysis of Variance (ANOVA) were conducted for each sub-construct. The distributions of the constructs were tested for normality. Because the sub-constructs were not normally distributed nonparametric Kruskall Wallis tests was used instead of ANOVA.

From the Kruskall Wallis analyses probability values ( $p$-values) were produced. A 'p-value' smaller than 0.05 indicates a significant difference between the means of the dimension tested for the spectator groups at a 95 per cent level of confidence.

Only significant differences are shown in Table 4:

Table 4. Sub-Constructs - Significance

\begin{tabular}{lcccc}
\hline Sub-construct & Chi-Square value & df & p-value & Significance \\
\hline Ease of use score & 51.45 & 2 & $<0.0001$ & Highly significant \\
Usefulness & 13.75 & 2 & 0.0010 & Highly significant \\
Attitude & 8.02 & 2 & 0.0181 & Significant \\
Intention to use & 14.12 & 2 & 0.0009 & Highly significant \\
Accessibility score & 10.70 & 2 & 0.0047 & Highly significant \\
\hline
\end{tabular}

Significant differences between the age-groups exist for all the sub-constructs. 


\section{Lecturers' Usage Of Social Media}

The overall usage was calculated by coding all the lecturers that used ANY of the social media platforms as 'Use' and lecturers that didn't use ANY of the social media platforms as 'Do not use', as indicated in Figure 2.

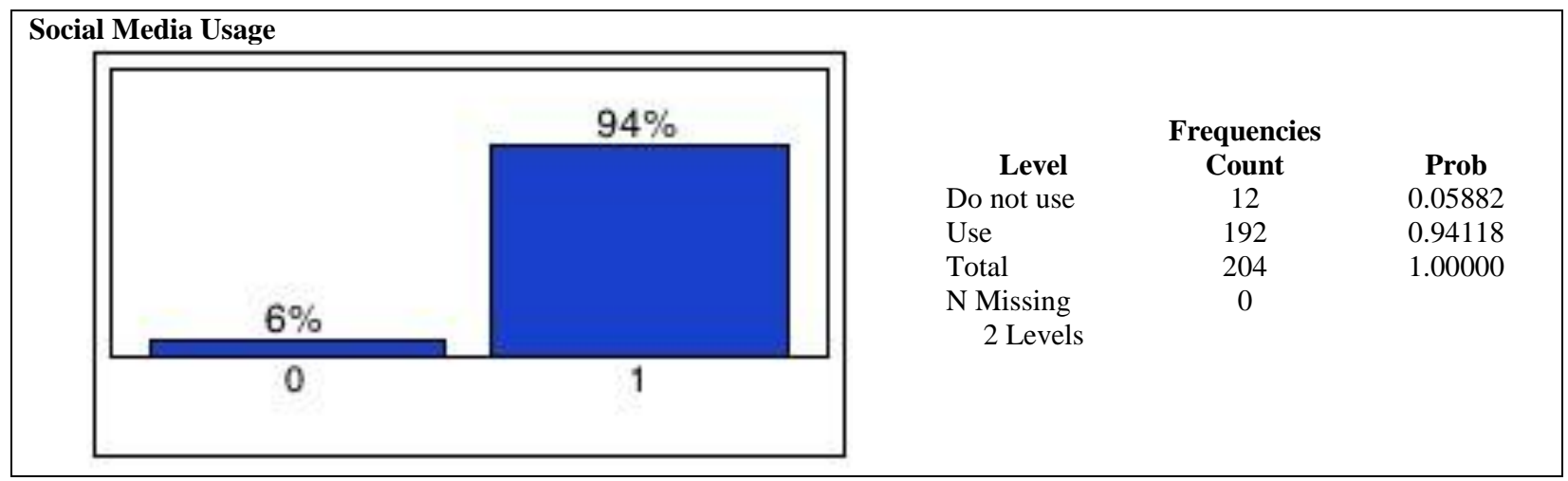

Figure 2. Social Media Usage

Only 5.9 per cent of lecturers didn’t use any social media.

\section{The Utilisation Of Social Media By Lecturers'}

To determine the utilisation of social media, respondents were asked to indicate the hours of usage per week in categories (no usage, 0-5 hours, 6-10 hours, 11-15 hours, 16-20 hours and more than 21 hours). The social media platforms were included in the study are Facebook; Twitter; MySpace; LinkedIn and Pinterest. Table 5 demonstrates the usage of social media.

Table 5. Usage Of Social Media By Lecturers'

\begin{tabular}{lcc|cc}
\hline & \multicolumn{3}{c|}{ Do not use } & \multicolumn{2}{c}{ Use } \\
\hline Facebook & $\mathbf{N}$ & \% of Total & N & \% of Total \\
Twitter & 32 & $15.69 \%$ & 172 & $84.31 \%$ \\
MySpace & 78 & $38.24 \%$ & 126 & $61.76 \%$ \\
LinkedIn & 102 & $50.00 \%$ & 102 & $50.00 \%$ \\
Pinterest & 79 & $38.73 \%$ & 125 & $61.27 \%$ \\
\hline
\end{tabular}
respondents.

Most respondents used Facebook (84.31 per cent) while only MySpace is used by (50 per cent) of the

Table 6 demonstrates the usage by hours per week of lecturers using social media.

Table 6. Lecturers' Usage Of Social Media, Categorised By Hours Per Week

\begin{tabular}{lccccc}
\hline \multirow{2}{*}{ Social Media Platform } & \multicolumn{4}{c}{ Hours } \\
\cline { 2 - 6 } & $\mathbf{0 - 5}$ & $\mathbf{6 - 1 0}$ & $\mathbf{1 1 - 1 5}$ & $\mathbf{1 6 - 2 0}$ & $\mathbf{2 1 +}$ \\
\cline { 2 - 6 } & \% of Total & \% of Total & \% of Total & \% of Total & \% of Total \\
\hline Facebook & $75.00 \%$ & $12.79 \%$ & $6.98 \%$ & $2.33 \%$ & $2.91 \%$ \\
Twitter & $88.10 \%$ & $8.73 \%$ & $0.79 \%$ & $1.59 \%$ & $0.79 \%$ \\
MySpace & $97.06 \%$ & $1.96 \%$ & $0.00 \%$ & $0.98 \%$ & $0.00 \%$ \\
LinkedIn & $84.00 \%$ & $11.20 \%$ & $2.40 \%$ & $2.40 \%$ & $0.00 \%$ \\
Pinterest & $95.41 \%$ & $1.83 \%$ & $1.83 \%$ & $0.92 \%$ & $0.00 \%$ \\
\hline
\end{tabular}

Most respondents used social media between 0 and 5 hours per week. A quarter ( 25 per cent) of the respondents uses Facebook more than five hours per week, whereas a small portion (2.94 per cent) use MySpace more than five hours per week. 


\section{Profiling The Usage Of Social Media By Respondents}

The biographical variables age, gender and population group were tested against the usage of social media. Of the biographical variables only age group showed significant differences in usage.

\section{Comparison Of The Respondents' Usage Of The Social Media Platforms}

Chi-Square tests were used to test for association between usage and the biographical variables. The purpose of a Chi-Square test is to test if any significant association exists between usage and a biographical variable.

\section{Comparison Of The Age Groups Usage Of The Social Media Platforms}

Figure 3 is a share chart that produces a visual representation of the association between usage and age group.

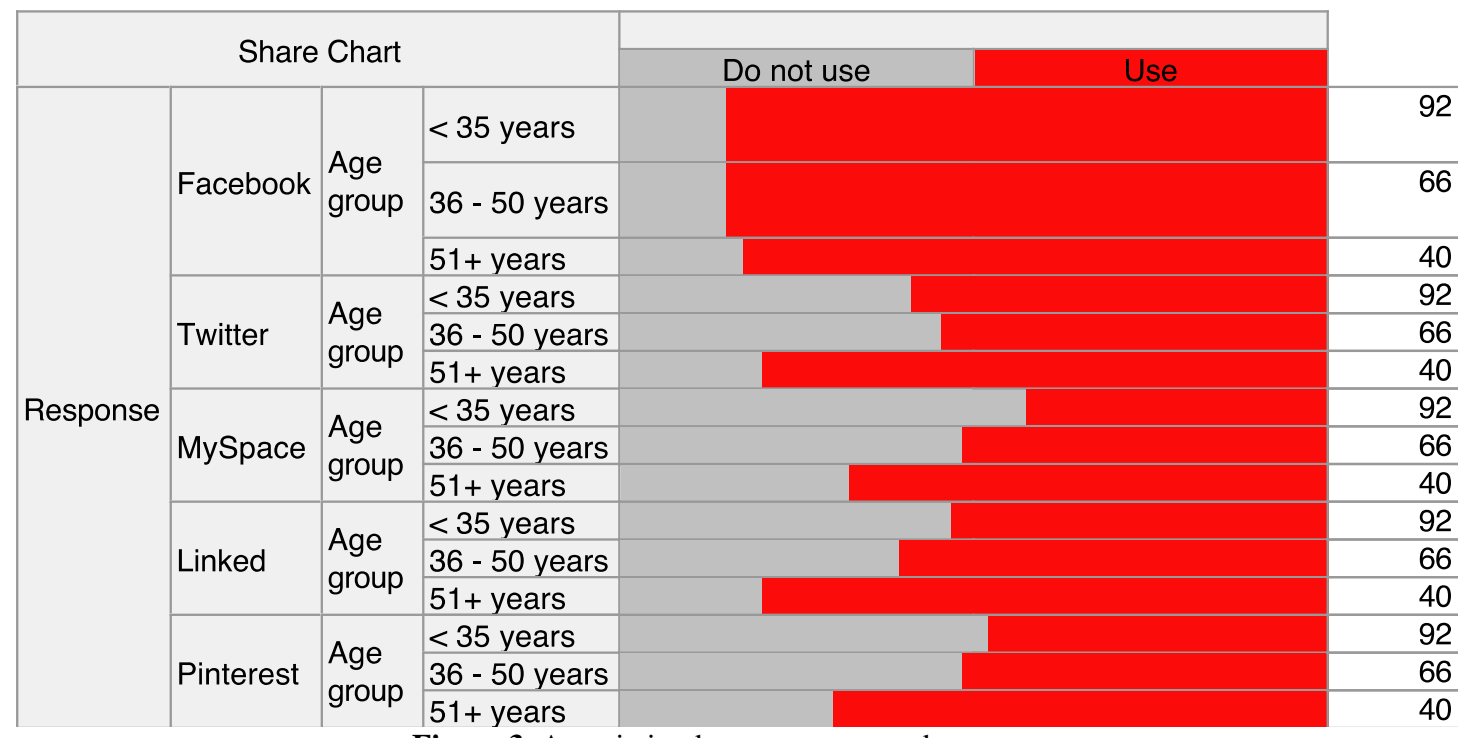

Figure 3. Association between usage and age group

From the Chi-Square tests probability values (p-values) were produced. A 'p-value' smaller than 0.05 , indicates a significant association between the biographical variable and usage at a 95 per cent level of confidence.

Only significant differences for age groups are shown in Table 7:

Table 7. Significant Differences Between Age Groups

\begin{tabular}{lcccc}
\hline $\begin{array}{l}\text { Social Media Differences } \\
\text { Between Age Groups }\end{array}$ & Chi-Square value & df & p-value & Significance \\
\hline Twitter & 7.44 & 2 & 0.0242 & Significant \\
MySpace & 7.07 & 2 & 0.0291 & Significant \\
LinkedIn & 8.40 & 2 & 0.0150 & Significant \\
Pinterest & 5.67 & 2 & 0.0586 & Not Significant Borderline \\
\hline
\end{tabular}

Significant associations exist between age-group and Twitter, MySpace and LinkedIn usage.

Table 8 shows the difference in Twitter usage between the age groups. As seen in the table, the proportion of lecturers that use Twitter is much higher for respondents 51 years and older $(32 / 40=80$ per cent) than the other age groups ( $<35$ years: $36 / 92=54.55$ per cent and $36-50$ years: $54 / 92=58.70$ per cent). 
Table 8. Age Group Usage Of Twitter

\begin{tabular}{|c|c|c|c|c|c|}
\hline & & $<35$ years & $36-50$ years & $51+$ years & \\
\hline \multirow{4}{*}{ Do not use } & Count & 38 & 30 & 8 & 76 \\
\hline & Total \% & 19.19 & 15.15 & 4.04 & 38.38 \\
\hline & Col \% & 41.30 & 45.45 & 20.00 & \\
\hline & Row $\%$ & 50.00 & 39.47 & 10.53 & \\
\hline \multirow{6}{*}{ Use } & Count & 54 & 36 & 32 & 122 \\
\hline & Total $\%$ & 27.27 & 18.18 & 16.16 & 61.62 \\
\hline & Col \% & 58.70 & 54.55 & 80.00 & \\
\hline & Row $\%$ & 44.26 & 29.51 & 26.23 & \\
\hline & Count & 92 & 66 & 40 & 198 \\
\hline & Total \% & 46.46 & 33.33 & 20.20 & \\
\hline
\end{tabular}

As seen in Table 9, the proportion of lecturers that use MySpace is much higher for respondents 51 years and older $(27 / 40=67.50 \%)$ than the other age groups $(<35$ years: $39 / 92=42.39 \%$ and $36-50$ years: $34 / 66=51.52 \%)$.

Table 9. Age Group Usage Of Myspace

\begin{tabular}{lccccc}
\hline & & $<$ 35 years & 36 - 50 years & 51+ years & \\
\hline \multirow{3}{*}{ Do not use } & Count & 53 & 32 & 13 & 98 \\
& Total \% & 26.77 & 16.16 & 6.57 & 49.49 \\
\hline \multirow{4}{*}{ Use } & Col \% & 57.61 & 48.48 & 32.50 & 13.27 \\
& Row \% & 54.08 & 32.65 & 27 & 100 \\
& Count & 39 & 34 & 17.64 & 50.51 \\
& Total \% & 19.70 & 51.52 & 67.50 & 17 \\
& Col \% & 42.39 & 34.00 & 27.00 & 40 \\
\end{tabular}

As seen in Table 10, the proportion of lecturers that use LinkedIn is much higher for respondents 51 years and older $(32 / 40=80 \%)$ than the other age groups $(<35$ years: $49 / 92=53.26 \%$ and $36-50$ years: $40 / 66=60.61 \%)$.

Table 10. Age Group Usage Of Linkedin

\begin{tabular}{|c|c|c|c|c|c|}
\hline & & $<35$ years & $36-50$ years & $51+$ years & \\
\hline \multirow{4}{*}{ Do not use } & Count & 43 & 26 & 8 & 77 \\
\hline & Total \% & 21.72 & 13.13 & 4.04 & 38.89 \\
\hline & $\mathrm{Col} \%$ & 46.74 & 39.39 & 20.00 & \\
\hline & Row \% & 55.84 & 33.77 & 10.39 & \\
\hline \multirow{6}{*}{ Use } & Count & 49 & 40 & 32 & 121 \\
\hline & Total \% & 24.75 & 20.20 & 16.16 & 61.11 \\
\hline & $\mathrm{Col} \%$ & 53.26 & 60.61 & 80.00 & \\
\hline & Row \% & 40.50 & 33.06 & 26.45 & \\
\hline & Count & 92 & 66 & 40 & 198 \\
\hline & Total \% & 46.46 & 33.33 & 20.20 & \\
\hline
\end{tabular}

\section{Comparison Of Males And Females Usage Of The Social Media Types} group.

Figure 4 is a Share chart that produces a visual representation of the association between usage and age 


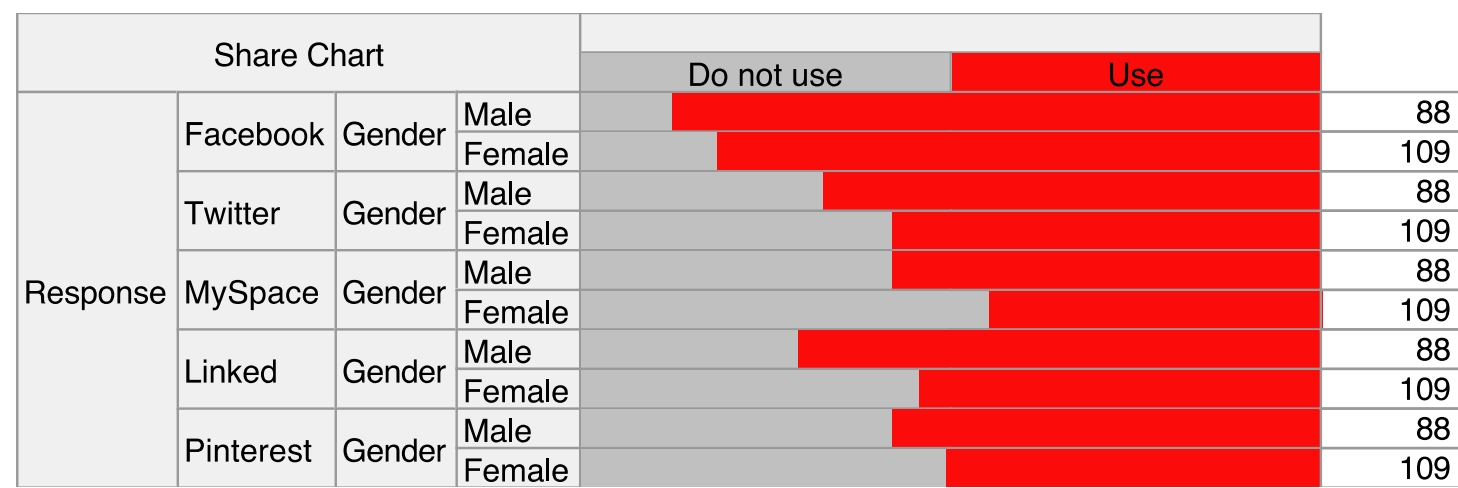

Figure 4. Comparison Of Males And Females Usage Of The Social Media Types

From the Chi-Square tests probability values (p-values) were produced. A 'p-value' smaller than 0.05 , indicates a significant association between the biographical variable and usage at a 95 per cent level of confidence.

Only significant differences for age group are shown in Table 11:

Table 11: Significant Differences Between Male And Female

\begin{tabular}{lcccc}
\hline $\begin{array}{l}\text { Social Media } \\
\text { Between Males And Females }\end{array}$ & $\begin{array}{c}\text { Differences } \\
\text { Chi-Square value }\end{array}$ & df & P-value & Significance \\
\hline LinkedIn & 8.40 & 2 & 0.0150 & Significant \\
\hline
\end{tabular}

Table 12 below shows the difference in LinkedIn usage amongst male and female lecturing staff.

Table 12. Gender Usage Of Linkedin

\begin{tabular}{lcccc}
\hline & & Male & Female & \\
\hline \multirow{3}{*}{ Do not use } & Count & 26 & 50 & 76 \\
& Total \% & 13.20 & 25.38 & 38.58 \\
& Col \% & 29.55 & 45.87 & 65.79 \\
Use & Row \% & 34.21 & 59 & 121 \\
& Count & 62 & 29.95 & 61.42 \\
\hline & Total \% & 31.47 & 54.13 & \\
& Col \% & 70.45 & 48.76 & 199 \\
& Row \% & 51.24 & 55.33 & 197 \\
\hline
\end{tabular}

Table 12 clearly shows that the proportion of lecturers that use LinkedIn is much higher for male respondents $(62 / 88=70.45 \%)$ than female respondents $(59 / 109=54.13 \%)$.

\section{CONCLUSION}

It is evident that technology changes on a continuous basis and that people are today more aware of the different technology systems available, as well as eager to use these technology systems. Mangold and Faulds (2009:357) mentioned that the internet has equipped many people, students, lecturers and institutions around the world to communicate on a more effective way with each other at any point in time. Davis (2010) indicated that social media allows students to instant-message their friends, classmates and lecturers with questions on study material at any time of the day or night. This enables students to study at a faster pace and ensures that they truly understand their study material. Therefore, it becomes evident that the use of social media networking systems in tertiary institutions does not only make communication easier between the lecturers and the students, but it can also add a lot of value in encouraging discussions between and among lecturers and students (Moran et al., 2011:4; Adamson, 2012). Fine (2011) indicated that lecturers that are making social media part of their teaching plan do have a positive increase in students' engagement and collaboration in the classroom, have an increase in technological proficiency, and build better communication skills among their students. 
The findings of the study however revealed that the majority (94 per cent) of lecturing staff use social media and it is more for social than work purposes. Mostly, social media is used between 0 and 5 hours per week. Facebook is the most used social media platform. Furthermore there were no biographical differences in the use of social media, except for age groups. Lecturers in the age group 50+ used social media less than the other age groups. Female lecturing staff uses the different social media platforms more than their male counter parts except for LinkedIn. LinkedIn is used more by male lecturers.

The study further revealed that the respondents that use social media, considered all the constructs ('Ease of use', 'Attitude', 'Intention to use' and 'System accessibility') as significantly more important than the respondents that do not use social media. 'System accessibility' was considered most important with a mean of 5.31, while 'Intention to use' were least important with a mean of 4.43.

The results however suggested that there were biographical differences for age-group and gender. No differences were found in the proportion of use of Facebook between the age-groups, although differences in the proportions for Twitter, LinkedIn and MySpace were found. Interestingly the older age group 51+ use Twitter, LinkedIn and MySpace more than the other age groups.

Younger lecturers have generally a higher acceptance of social media than their older colleagues. It is therefore recommended that training programmes should be developed in order to aid lecturers in the use of social media for educational purposes - especially for older lecturers, as this will ensure the effective utilisation of lecturing resources. Educational institutions should further develop strategies and tactics to make social media platforms more attractive for lecturers, in order for them to use it for educational purposes. However, it is important that the use of social media platforms in an educational environment - lecturer to student - should be monitored and guided by institutional policies and guidelines, in order to ensure that it is being used effectively and for the right reasons.

\section{AUTHOR INFORMATION}

Prof. Johannes A. Wiid is a Professor in the Department of Marketing and Retail Management at the University of South Africa (Unisa). He has published numerous articles in refereed journals and is the editor and author of various marketing related textbooks. These books are widely prescribed at universities in South Africa. He holds a DCom in Marketing from the University of Johannesburg.

Corinne E. Nell is a lecturer in the Department of Marketing and Retail Management at the University of South Africa (Unisa). She has worked in the retail sector in South Africa for many years and therefore developed an interest in retailing. Her Academic interests include retailing with a specific focus on visual merchandising and store atmospherics, consumer behaviour, social media and consumers' perception. She holds a MCom in Marketing Management from the University of South Africa.

Prof. Michael C. Cant is the head of the Department of Marketing and Retail Management at the University of South Africa (Unisa). He has published over 50 accredited articles in refereed journals and is the editor and author of numerous marketing textbooks. These books are widely prescribed at universities in South Africa. He has presented papers at more than 45 international conferences all over the world and is a well respected marketing and retail scholar. He holds a DCom in Marketing from the University of South Africa.

\section{REFERENCES}

1. Adamson, C. (2012). The Role of Social Media in Education. Retrieved from: http://www.icwe.net/oeb_special/OEB_Newsportal/the-role-of-social-and-mobile-media-in-education/

2. Boyd, D.M. \& Ellison, N.B. (2008). Social network sites: definition, history, and scholarship. Journal of computer-mediated communication, 13(1), 210-230.

3. Davis, F.D., Bagozzi, R.P. \& Warshaw, P.R. (1989). User Acceptance of Computer Technology: Comparison of Two Theoretical Models, Management Science, 35(8):982-1003. 
4. Davis, F.D. (1993). User acceptance of information technology: system characteristics, user perceptions and behavioural impacts. International Journal of Man-Machine Studies, 38(1), 475-487.

5. Davis, M.R. (2010). Social Networking Goes to School. Retrieved from: http://www.edweek.org/dd/articles/2010/06/16/03networking.h03.html

6. $\quad$ Fine, V. (2011). Social Networking In Schools: Educators Debate The Merits Of Technology In Classrooms. Retrieved from: http://www.huffingtonpost.com/2011/03/27/social-networkingschools_n_840911.html

7. Jackson, C. (2011). Teaching Tolerance: Your students love social media and so can you. Retrieved from: http://www.tolerance.org/magazine/number-39-spring-2011/feature/your-students-love-social-media-andso-can-you

8. Larson, D. (2012). Infographic: Spring 2012 Social Media user Statistics. Retrieved from: http://blog.tweetsmarter.com/social-media/spring-2012-social-media-user-statistics/

9. Lepi, K. (2012). 25 Ways teachers can integrate social media into education. Retrieved from: http://edudemic.com/2012/07/a-teachers-guide-to -social-media/

10. Mangold, W.G. \& Faulds, D.J. (2009). Social Media: the new hybrid element of the promotion mix. Business Horizons, 52(1), 357-365.

11. Mazhar, N. (2006). Technology Acceptance Model. Retrieved from: http://ezinearticles.com/?TechnologyAcceptance-Model\&id=202354

12. Moran, M., Seaman, J. \& Tinti-Kane, H. (2011). Teaching, Learning and Sharing: How today's higher education faculty use social media. Retrieved from:

http://www.pearsonlearningsolutions.com/educators/pearson-social-media-survey-2011-bw.pdf

13. Picardo, J. (2011). Teaching and Learning with Social Networks: barriers to Adoption. Retrieved from: http://www.josepicardo.com/2011/08/teaching-and-learning-with-social-networks-barriers-to-adoption/

14. Shen, D., Laffey, J., Lin, Y. \& Huang, X. (2006). Social influence for perceived usefulness and ease-of-use of course delivery systems. Journal of Interactive Online Learning, 5(3), 270-282.

15. Venkatesh, V. (2013). Unified Theory of Acceptance and Use of Technology (UTAUT). Retrieved from: http://www.vvenkatesh.com/it/organizations/theoretical_models.asp

16. Wiid, J.A., Nell, E.C., Cant, M.C. (2014). Perceptions and uses of social media networking systems by South African students. International Business \& Economics Research Journal, 13(4), 715-726. 